\title{
1,3-Dibromo 5,5-dimethylhydantoin (DBH)-Catalyzed Solvent-Free Synthesis of 2-arylbenzimidazoles under Microwave Irradiation
}

\author{
MEHDI FOROUZANI $^{* 1}$ and HASSAN GHASEMNEJAD-BOSRA ${ }^{2}$ \\ ${ }^{1}$ Department of Chemistry, Payamenoor University, 19395-4697, Tehran, I.R. of Iran \\ ${ }^{2}$ Department of Chemistry, Islamic Azad University-Babol Branch, P.O. Box 755, Babol \\ 47188-33348, Iran \\ Forouzanimehdi@yahoo.com
}

Received 5 November 2011; Accepted 15 January 2012

\begin{abstract}
An expeditious synthesis of 2-aryl-benzimidazoles by the condensation of $o$-phenylenediamine with various arylaldehydes is described. This greener protocol is catalyzed by 1,3-Dibromo 5,5-dimethylhydantoin (DBH), and proceeds efficiently in the absence of any organic solvent under thermal condition and microwave irradiation in high yields.
\end{abstract}

Keywords: 1,3-Dibromo 5,5-dimethylhydantoin (DBH), Benzimidazoles, Microwave irradiation, Solvent free.

\section{Introduction}

Benzimidazoles are very useful intermediates for the development of molecules of pharmaceutical and biological interest. Substituted benzimidazole derivatives have found applications in diverse therapeutic areas including antiulcers, antihyperten-sives, antivirals, antifungals, anticancers, and antihistaminics ${ }^{1,2}$. The widespread interest in benzimidazole containing structures has prompted extensive studies for their synthesis. There are two general methods for the synthesis of 2-substituted benzimidazoles. One is the coupling of $o$ phenylenediamines and carboxylic $\operatorname{acids}^{3}$ or their derivatives (nitriles, imidates, or orthoesters), which often require strong acidic conditions and sometimes combine with very high temperatures (i.e., PPA, $\left.180^{\circ} \mathrm{C}\right)^{4,5-6}$. The other way involves a two-step procedure that includes the oxidative cyclodehydrogenation of aniline Schiff's bases, which are often generated in situ from the condensation of $o$-phenylenediamines and aldehydes ${ }^{7-12}$. However, suffer from longer reaction times, unsatisfactory yields, harsh reaction conditions and excessive use of reagents and catalysts. It is therefore important to find more convenient methods for the preparation of these compounds.

Microwave-assisted organic synthesis ${ }^{13}$ (MAOS) has attracted considerable interest and is an important technique in green synthetic chemistry. It could help achieve high yields and clean reaction out comes at shorter action time. Organic solvent- free reaction conditions eliminate the toxicity and flammability issues associated with common solvents. Together, 
solvent-free organic syntheses assisted by microwave irradiation (MW) have being regarded as environmentally benign methodologies.

\section{Experimental}

All the reactions were carried out using a conventional (unmodified) microwave oven (LG, $230 \mathrm{~V}, \sim 50 \mathrm{~Hz}$ ). Reactions were monitored on TLC by comparison with the samples prepared by known procedures. The Infrared spectroscopy (IR) spectra were recorded using a Shimadzu 435-U-04 spectrophotometer (KBr pellets) and the Nuclear magnetic resonance (NMR) spectra were obtained in using a $90 \mathrm{MHz}$ JEOL FT NMR spectrometer. All melting points were determined on a Büchi 530 melting point apparatus and are reported uncorrected.

Microwave experiments were conducted using a CEM Discover monomode oven operating at $2450 \mathrm{MHz}$ monitored by a PC computer, and temp. was maintained at a constant value by power modulation $(0-300 \mathrm{~W})$. Stirring was provided by an in situ magnetic stirrer. Reactions were performed in open glass vessels (capacity $10 \mathrm{~mL}$ ). Reaction conditions: power $300 \mathrm{~W}$; no solvent; ramp time $3 \mathrm{~min}$; hold time $10 \mathrm{~min}$; stirring on; temp. $145^{\circ} \mathrm{C}$.

\section{General Procedure for the Synthesis of 2-aryl-benzimidazoles (Method A)}

To a mixture of $o$-phenylenediamine $(1 \mathrm{mmol})$, aldehyde $(1 \mathrm{mmol})$ and 1,3-dibromo 5,5dimethyl hydantoin (DBH) $(0.12 \mathrm{mmol}, 0.34 \mathrm{mg})$ was added and the mixture was inserted in an oil bath and heated at $50^{\circ} \mathrm{C}$ for the appropriate time (Table 1). Completion of the reaction was indicated by Thin Layer Chromatography (TLC). After which dichloromethane (10 ml) was added to the mixture and left aside for a few minutes, the solid thus separated was recrystallized from methanol or subjected to silica gel column chromatography to get the pure product/s.

\section{General Procedure for the Synthesis of 2-aryl-benzimidazoles (Method B)}

A mixture of $o$-phenylenediamine $(1 \mathrm{mmol})$, aldehyde $(1 \mathrm{mmol})$ and 1,3 -dibromo 5,5dimethyl hydantoin (DBH) $(0.12 \mathrm{mmol}, 0.34 \mathrm{mg})$ was taken in the special open glass vessel. The mixture was thoroughly mixed, and the tube was then subjected to microwave irradiation according to the above protocol. (see Table 1). After which dichloromethane (10 $\mathrm{ml}$ ) was added to the mixture and left aside for a few minutes, the solid thus separated was recrystallized from methanol or subjected to silica gel column chromatography to get the pure product/s.

The products were characterized on the basis of their physical and spectral analysis and by direct comparison with literature data ${ }^{14-17}$.

\section{Results and Discussion}

In continuation with the search for simple non-hazardous methods for the transformations in organic synthesis using halogenating agents ${ }^{18-26}$, herein we report a highly versatile and efficient synthesis of 2-aryl-benzimidazoles 3 from $o$-phenylenediamine, aldehyde and catalytic amounts of 1,3-dibromo 5,5-dimethyl hydantoin (DBH) under solvent-free and microwave conditions in high yields (Scheme 1).

To find out the optimum quantity of 1,3-dibromo 5,5-dimethyl hydantoin (DBH), the reaction of $o$-phenylenediamine and benzaldehyde was carried out under thermal solventfree conditions (Method A) using different quantities of DBH (Table 1). As shown this table, 0.12 mmole of DBH gave excellent yield in 95 as can be seen from Table 1 . Thus, we prepared arrange of benzimidazoles under the optimized reaction conditions: $O$ phenylenediamine $(1 \mathrm{mmol})$ and aldehyde $(1 \mathrm{mmol})$ in the presence of $\mathrm{DBH}(0.12 \mathrm{mmol})$. A 
series of benzimidazoles were prepared in high to excellent yields by two methods (A, B) (Table 2).<smiles>[R]c1ccc(C=O)cc1</smiles>

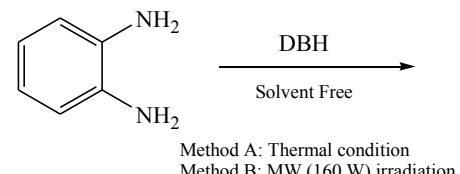

2 Method A: Thermal condition
Method B: MW $(160 \mathrm{~W})$ irradiation<smiles>[R]c1ccc(-c2nc3ccccc3[nH]2)cc1</smiles>

\section{Scheme 1}

Table 1. The effect of amount of DBH on the reaction of $o$-phenylenediamine and benzaldehyde under thermal solvent free conditions.

\begin{tabular}{cccc}
\hline Entry & Catalyst $(\mathrm{mmol})$ & Time $(\mathrm{min})$ & Yield $^{\mathrm{a}}(\%)$ \\
\hline 1 & 0 & 120 & 0 \\
2 & 0.05 & 85 & 51 \\
3 & 0.1 & 60 & 87 \\
4 & 0.12 & 45 & 95 \\
5 & 0.15 & 45 & 95 \\
6 & 0.20 & 45 & 95 \\
\hline
\end{tabular}

${ }^{\mathrm{a}}$ Yields refer to the pure isolated products.

To account for the facile formation of benzimidazoles, the following mechanism (Scheme 2) is proposed. The reaction between an aldehyde and a diamine leads to the formation of Schiff base (I) which is stabilized by catalyze. Intermolecular attack by the second amino group on $\mathrm{C}=\mathrm{N}$ double bond facilitates the formation of hydro-benzimidazole (II) which undergoes subsequent air oxidation ${ }^{23}$ to give the desired benzimidazole as the final product.

Table 2. DBH catalyzed synthesis of benzimidazoles.

\begin{tabular}{|c|c|c|c|c|c|}
\hline Entry & Product $^{\mathrm{a}}$ & $\mathrm{R}$ & $\begin{array}{c}\text { Method A } \\
\text { Time/Yields } \\
(\%)^{\mathrm{b}}\end{array}$ & $\begin{array}{c}\text { Method B } \\
\text { Time/Yields } \\
(\%)^{b}\end{array}$ & M.p., ${ }^{\circ} \mathrm{C}$ (Lit.) ${ }^{\mathrm{c}}$ \\
\hline 1 & $\mathbf{3 a}$ & $\mathrm{H}$ & $(45 \mathrm{~min} / 95)$ & $(5 \mathrm{~min} / 93)$ & $287-288(288-190)$ \\
\hline 2 & 3b & 4-Me & $(48 \mathrm{~min} / 93)$ & $(6 \mathrm{~min} / 94)$ & $278-280(277-279)$ \\
\hline 3 & $3 c$ & 3-Me & $(49 \min / 92)$ & $(8 \min / 93)$ & $215-217(217-219)$ \\
\hline 4 & 3d & 4-OMe & $(52 \mathrm{~min} / 94)$ & $(5 \mathrm{~min} / 90)$ & $226-228(227-228)$ \\
\hline 5 & $3 e$ & 3-OMe & $(54 \mathrm{~min} / 89)$ & $(6 \mathrm{~min} / 95)$ & $211-213(210-210.4)$ \\
\hline 6 & $3 f$ & $3,4-\mathrm{OMe}_{2}$ & $(58 \mathrm{~min} / 89)$ & $(9 \mathrm{~min} / 89)$ & $178-180(178-179)$ \\
\hline 7 & $3 g$ & $4-\mathrm{N}(\mathrm{Me}) 2$ & $(52 \mathrm{~min} / 90)$ & $(7 \mathrm{~min} / 93)$ & $250-251(252-254)$ \\
\hline 8 & $3 \mathrm{~h}$ & $4-\mathrm{NO}_{2}$ & $(44 \mathrm{~min} / 94)$ & $(9 \mathrm{~min} / 92)$ & $297-299(298-300)$ \\
\hline 9 & $3 \mathbf{i}$ & $3-\mathrm{NO}_{2}$ & $(41 \mathrm{~min} / 93)$ & $(8 \mathrm{~min} / 89)$ & $205-207$ (204-206) \\
\hline 10 & $3 \mathbf{j}$ & $2-\mathrm{NO}_{2}$ & $(43 \mathrm{~min} / 95)$ & $(6 \mathrm{~min} / 90)$ & $169-170(168-170)$ \\
\hline 11 & $3 \mathbf{k}$ & $4-\mathrm{Cl}^{2}$ & $(45 \mathrm{~min} / 94)$ & $(5 \mathrm{~min} / 94)$ & $191-193(192-293)$ \\
\hline 12 & 31 & $2-\mathrm{Cl}$ & $(47 \mathrm{~min} / 92)$ & $(6 \mathrm{~min} / 92)$ & $156-158(155-156)$ \\
\hline 13 & $3 \mathrm{~m}$ & $3-\mathrm{F}$ & $(43 \mathrm{~min} / 93)$ & $(7 \mathrm{~min} / 93)$ & $221-223(220-222)$ \\
\hline 14 & $3 n$ & $4-\mathrm{F}$ & $(42 \min / 96)$ & $(6 \mathrm{~min} / 92)$ & $202-203(203-205)$ \\
\hline 15 & 30 & $2-\mathrm{OH}$ & $(40 \mathrm{~min} / 94)$ & $(7 \mathrm{~min} / 95)$ & $235-236(236-237)$ \\
\hline
\end{tabular}

a) Isolated yields. b) All the products are known, characterized by IR, NMR spectral analysis and compared with the authentic samples. c) Melting points of compounds are consistent with reported values ${ }^{14-16,27}$. 
The compares the efficiency of DBH (time, yield, reaction conditions) with the efficiency of some other catalysts used in the synthesis of benzimidazoles (Table 3). It clearly shows that the presented method, using DBH as the catalyst, is simple, efficient and comparable with many catalytic systems for the synthesis of benzimidazoles derivatives.

Table 3. Comparison of efficiently various catalysts in the synthesis of benzimidazoles.

\begin{tabular}{|c|c|c|c|c|c|}
\hline Entry & Catalyst & Condition & $\begin{array}{c}\text { Time } \\
(\min )[\mathrm{h}]\end{array}$ & $\begin{array}{c}\text { Yield } \\
(\%)\end{array}$ & Reference \\
\hline 1 & $\overline{\mathrm{DBH}}$ & Solvent-free $/ 50^{\circ} \mathrm{C}$ & (45) & 95 & This work \\
\hline 2 & DBH & Solvent-free/MW & (5) & 93 & This work \\
\hline 3 & CAN (5 mol \%) & $\mathrm{PEG} / 50{ }^{\circ} \mathrm{C}$ & [2] & 98 & 28 \\
\hline 4 & Dowex $50 \mathrm{~W}$ & Water $/ 70{ }^{\circ} \mathrm{C}$ & [8] & 83 & 29 \\
\hline 5 & $\mathrm{Me}_{2} \mathrm{~S}^{+} \mathrm{BrBr}^{-}$ & $\mathrm{MCN} / \mathrm{r} . \mathrm{t}$ & [5] & 85 & 10 \\
\hline 6 & Polyaniline sulfate & $\mathrm{CH}_{2} \mathrm{CH}_{2} \mathrm{CL}_{2} /$ r.t & [2] & 92 & 12 \\
\hline 7 & $\mathrm{HCl}$ & Solvent-free/MW & (10) & 93 & 4 \\
\hline 8 & $\mathrm{SiO}_{2}-\mathrm{Pr}-\mathrm{SO}_{3} \mathrm{H}$ & Solvent-free/r.t & {$[1-2]$} & 90 & 30 \\
\hline 9 & $\mathrm{NaHSO}_{3}$ & DMAc/MW & (10) & 88 & 31 \\
\hline 10 & $\mathrm{SiO}_{2}-\mathrm{FeCl}_{3}$ & $\mathrm{H}_{2} \mathrm{O}_{2} / 150^{\circ} \mathrm{C}$ & (30) & 95 & 32 \\
\hline
\end{tabular}

The advantages or the characteristic aspects of the method described in this paper in comparison with other previously reported ones are the following: the yields of products were better than the previous reported yields and in addition, the catalyst DBH is inexpensive, has no moisture sensitivity, and no special measures are required for the reaction.

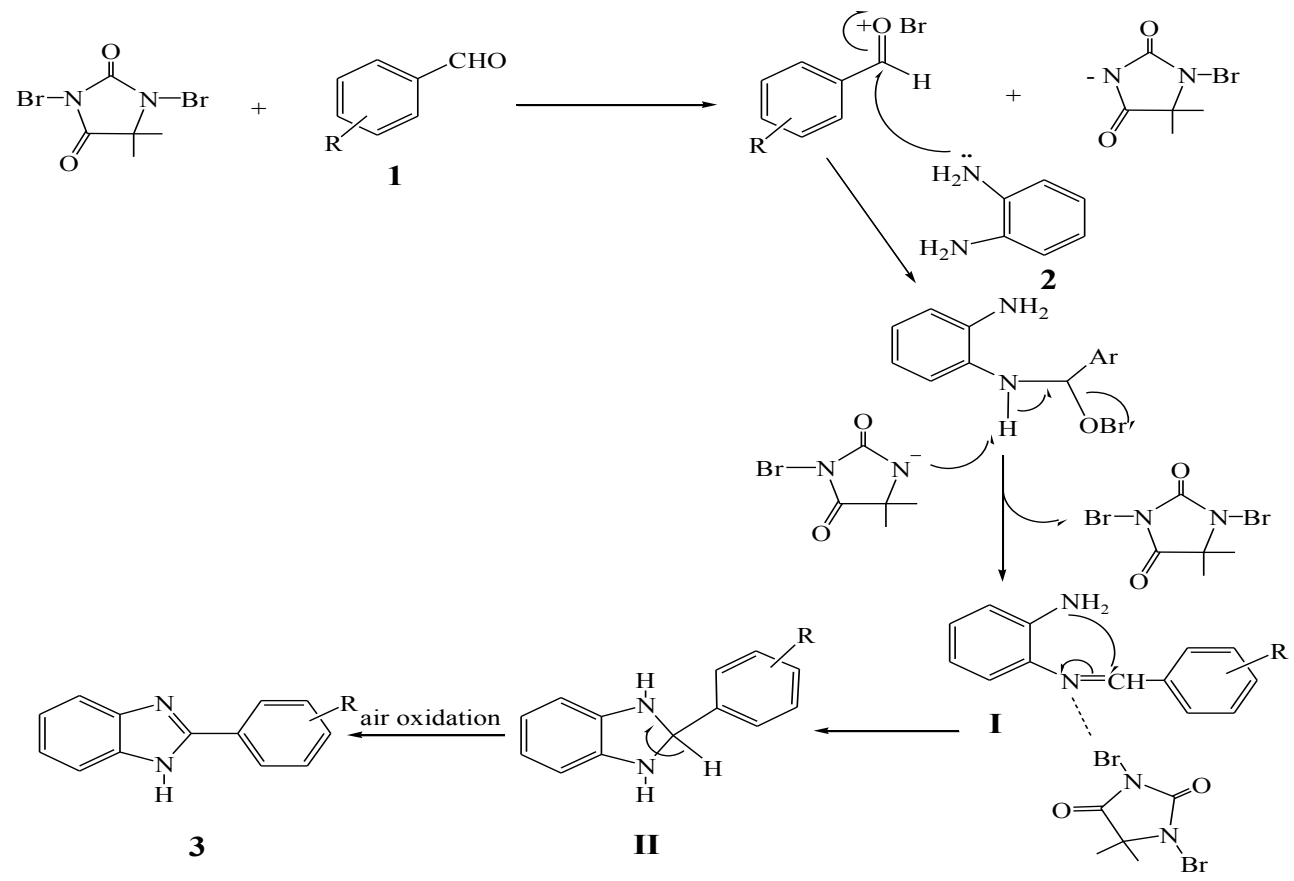

Scheme 2 


\section{Conclusion}

The present methodology shows that 1,3-dibromo 5,5-dimethyl hydantoin (DBH) is an efficient catalyst in the one-pot synthesis of benzimidazole derivatives. The main advantages of the presented protocol are mild, clean and environmentally benign reaction conditions, as well as the high yields. Furthermore, this method is also expected to find application in organic synthesis due to the low cost of the reagent. It is believed that this method will be a useful addition to modern synthetic methodologies.

\section{Acknowledgments}

We wish to thank the Department Chemistry-University of Payamnoor Sari, Sari, Iran, for financial support during the realization of this research.

\section{References}

1. Pasov A A, Yozhitsa I N, Bugaeva, L I, and Anisimova, V A, Pharm. Chem. J. 1999, 33, 232.

2. Roth T, Morningstar, M L, Boyer P L, Hughes S H, Buckheit R W Jr, and Michejda C J, J. Med. Chem. 1997, 40, 4199.

3. Wright J B Chem. Rev. 1951, 48, 397.

4. Wang R, Lu X, Yu X, Shi L, and Sun Y, J. Mol. Catal. A. Chem. 2007, 266, 198.

5. Fairley T A, Tidwell R R, Donkor I, Naiman N A, Ohemeng K A Lombardy R J, Bentley J A, and Cory M, J. Med. Chem. 1993, 36, 1746.

6. Beaulieu P L, Hache B and Von Moos E A, Synthesis 2003, 11, 1683.

7. Curini M, Epifano F, Montanari F, Rosati O, and Taccone S, Synlett 2004, 10, 1832.

8. Hornberger K R, Adjabeng G M, Dickson H D, and Davis-Ward R G, Tetrahedron Lett. 2006, 47, 5359.

9. Mirkhani V, Moghadam M, Tangestaninejad S, and Kargar H, Tetrahedron Lett. 2006, 47, 2129.

10. Das B, Holla H and Srinivas Y Tetrahedron Lett. 2007, 48, 61.

11. Wilfred C D and Taylor R J K, Synlett 2004, 9, 1628.

12. Srinivas U, Srinivas Ch, Narender P, Rao V J, and Palaniappan S, Catal Commun. 2007, 8, 107.

13. Michael D, Mingos P, and Baghurst D R, Chem. Soc. Rev, 1991, 20, 1.

14. Perumal S, Mariappan S, and Selvaraj S, ARKIVOC 2004, 8, 46.

15. Azarifar D, Pirhayati M, Malaki B, Sanginabadi M, and Yami R, J. Serb. Chem. Soc. 2010, 75(9), 1181.

16. Ravi V, Ramu E, Vijay K and Rao S, Chem. Pharm. Bull. 2007, 55, 1254.

17. Chakrabarty M, Karmakar S, Mukherji A, Arima S, and Harigay Y, Heterocycles 2006, 68, 967.

18. Azarifar D and Ghasemnejad-Bosra H, Synthesis 2006, 1123.

19. Azarifar D, Ghasemnejad-Bosra H, Zolfigol M A, and Tajbaksh M, Heterocycles 2006, 68, 175.

20. Ghasemnejad-Bosra H, Faraje M, Habibzadeh S, and Ramzaniyan-Lehmali F, J. Serb. Chem. Soc. 2010, 75, 299.

21. Ghasemnejad-Bosra H, Haghdadi M, and Gholampour-Azizi I, Heterocycles 2008, 75,391 .

22. Ghasemnejad-Bosra H, Haghdadi M, Khanmohamadi O, Gholipour M, and Asghari G, J. Chin. Chem. Soc. 2008, 55, 464. 
23. Ghasemnejad-Bosra H, Faraje M, and Habibzadeh S, Helv. Chim. Acta. 2009, 92, 575.

24. Ghasemnejad-Bosra H and Forouzani M, Heterocycl. Commun. 2011, 17(1-2), 83.

25. Habibzadeh S, Ghasemnejad-Bosra H, and Faraji M, Helv. Chim. Acta. 2011, 94, 429.

26. Forouzani M, Ghasemnejad-Bosra H, and Habibzadeh S, Science China Chemistry 2011, 6, 957.

27. Lin S and Yang L, Tetrahedron Lett. 2005, 46, 4315.

28. Kidwai M, Jahan A, and Bhatanagar D, J. Chem. Sci. 2010, 122, 607.

29. Mukhopadhyay Ch, Datta A, Butcher R J, Paul B K, Guchhait N, and Raghunath S, ARKIVOC 2009, 8, 1.

30. Ziarani M Gh, Badiei A, and Hassanzadeh M, International Journal of Applied Biology and Pharmaceutical Technology 2011, 2, 48.

31. López S E, Restrepo J, Pérez B, Ortiz Sh, and Salazar J, Bull. Korean Chem. Soc. 2009, 30, 1628.

32. Fazlinia A, Mosslemin M H, and Sadoughi H, J. Korean Chem. Soc. 2010, 54, 579. 


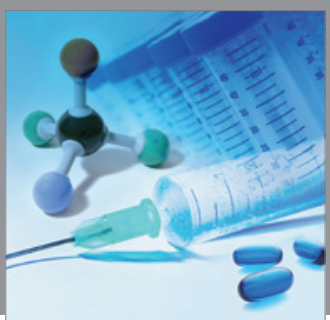

International Journal of

Medicinal Chemistry

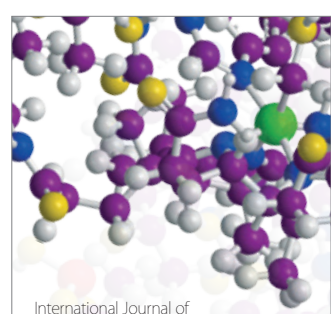

Carbohydrate Chemistry

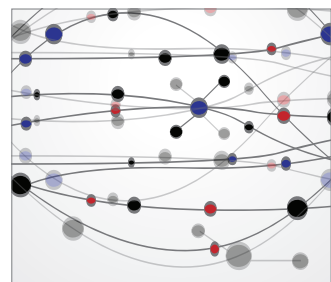

The Scientific World Journal
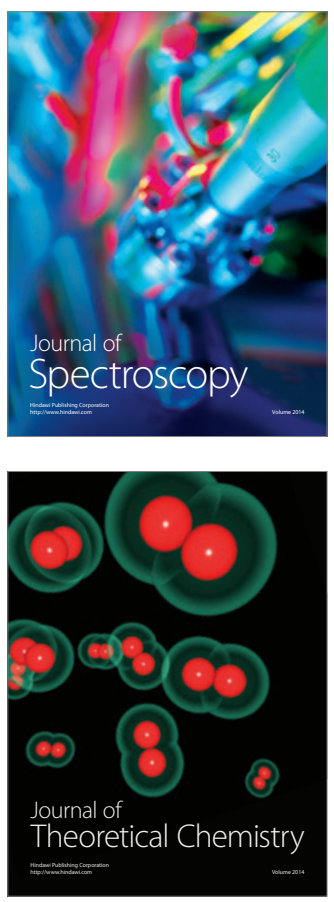
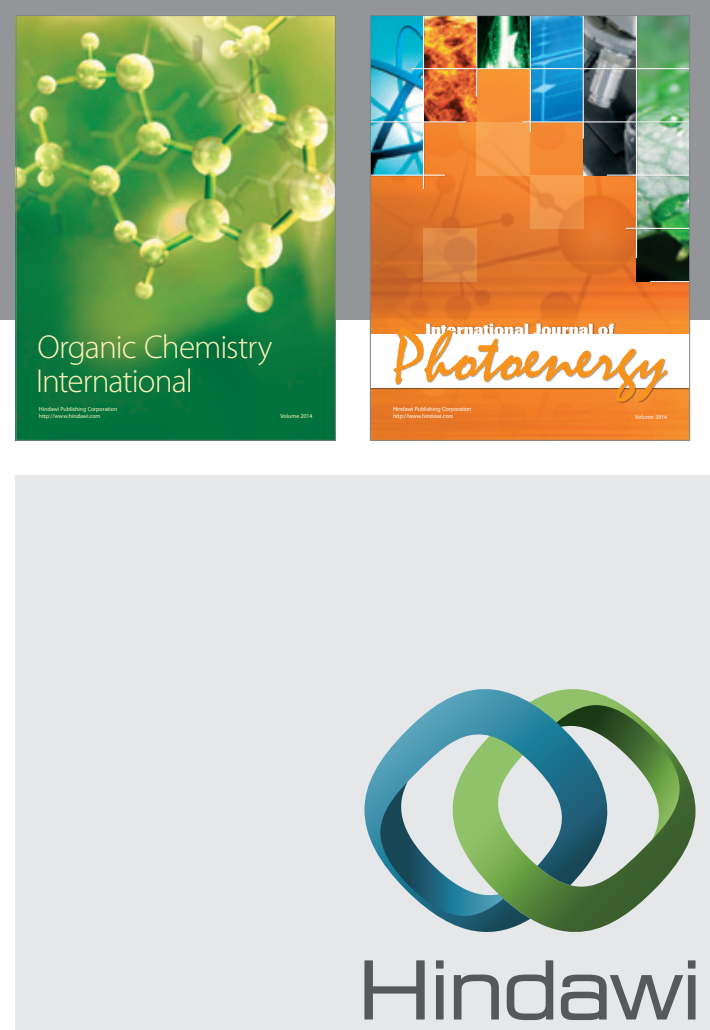

Submit your manuscripts at

http://www.hindawi.com
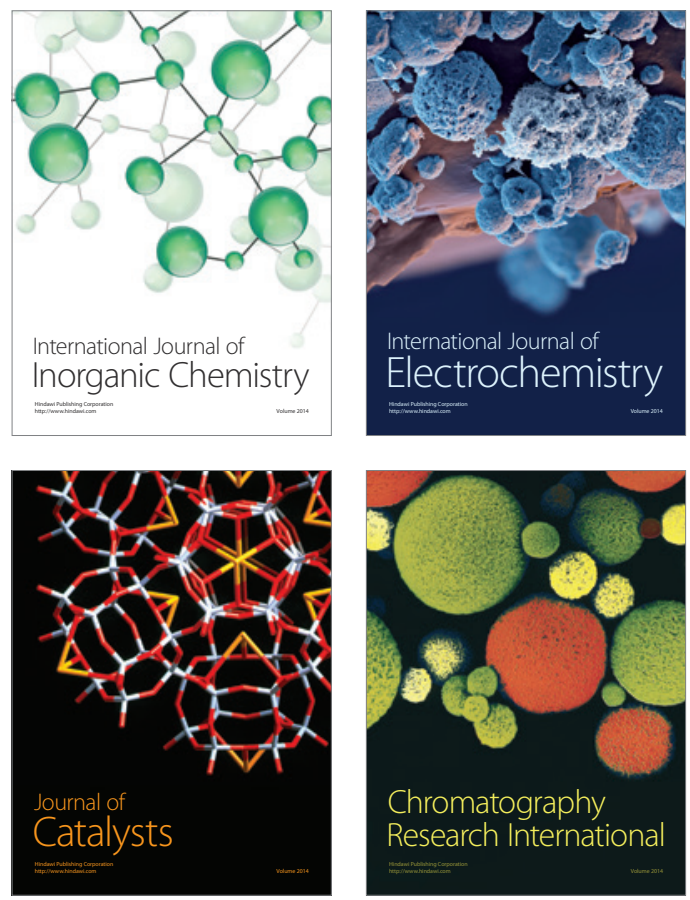
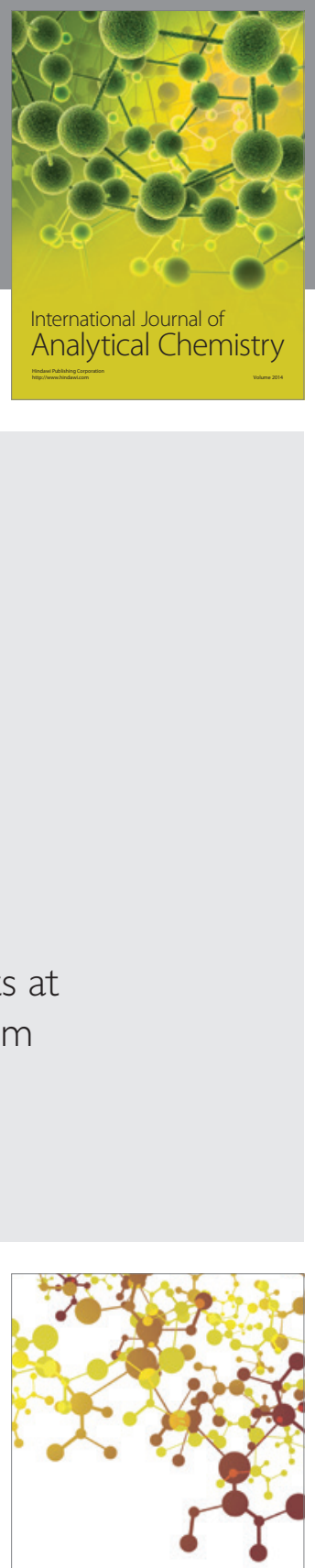

Journal of

Applied Chemistry
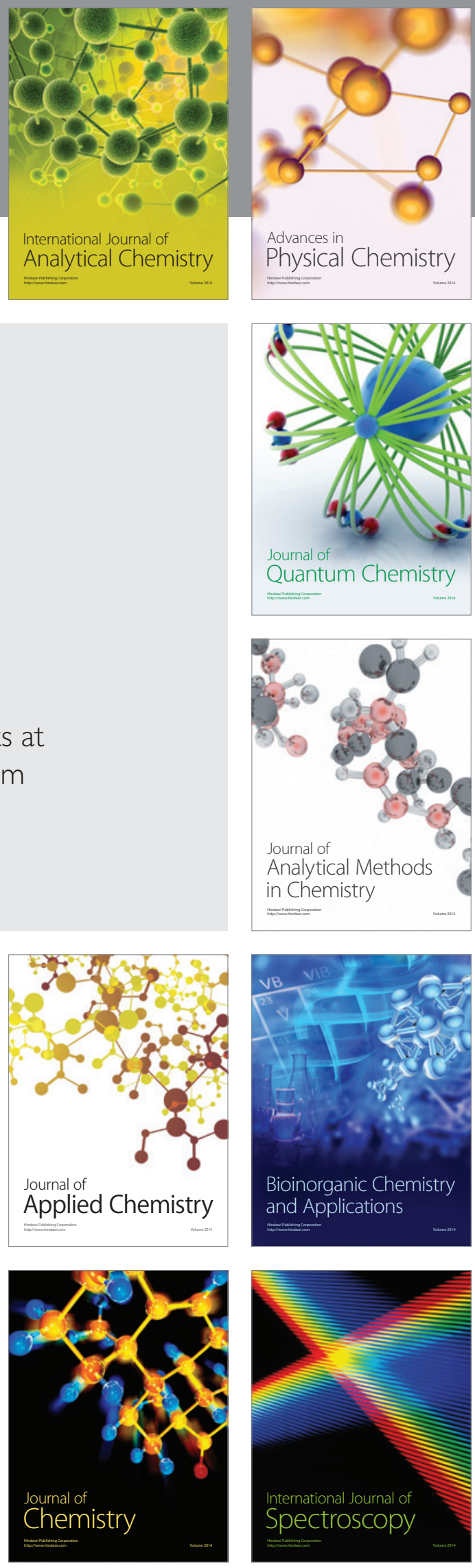